\title{
Open-Ended Apps in Kindergarten: Identity Exploration Through Digital Role-Play
}

\author{
George Brown College \\ LEAH BRATHWAITE \\ George Brown College \\ LISA HOBMAN \\ George Brown College \\ NICOLA MAGUIRE \\ George Brown College \\ EMMA MOGYORODI \\ Ryerson University
}

MONICA MCGLYNN-STEWART

\section{Abstract}

This 2-year research study followed 14 kindergarten classrooms in Ontario as they used open-ended tablet applications to support literacy learning. Through multimodal slideshows the children explored identities such as reporter, teacher, and architect during self-initiated role-play. The slideshows they created demonstrated multimodal productions that were longer, more complex, and more varied than their literacy production with traditional literacy tools and practices. Rather than supplanting traditional kindergarten meaning-making practices such as role-play, children folded digital affordances into their play in ways that expanded the range of identities they explored and the tools and practices with which they explored them.

\section{Introduction}

Mobile digital technologies have become "everyday objects" in the lives of many young children in Canada, both inside and outside of formal learning environments. There is a growing body of research into the various types and uses of digital technology (DT) for young children. Several recent studies describe how mobile DT, such as smartphones and tablets, are being used to support young children's literacy learning at home and school, and to create a school to home link (Blagogevic, Brumer, Chevalier, O'Clair, \& Thomas, 2012; Neumann, 2016; Radesky, Schimacker, \& Zuckerman, 2015; Wong, 2015). While some studies have examined the use of eBooks, games, digital drawing pens (Lee, Wu, \& Chen, 2017), augmented reality toys (Yilmaz, 2016) and learn-to-read apps, studies that report on the use of open-ended iPad apps in school environments are emerging (e.g., Fleer, 2014; Herro, 2015). In fact, several studies (e.g., Falloon \& Khoo, 2014; Harwood, 2017; Roswell \& Harwood, 2015) illustrate the dynamism with which DT is being explored in early learning classrooms as a way to redefine literacy acquisition, expression, development, and consolidation. 
However, in many early learning contexts such as pre-schools and kindergartens, DT may be largely absent due to the concern of early years educators that it may hinder young children's learning through play. There are many voices urging caution when using DT with young children, while simultaneously championing the potential of DT for children's learning. The National Association for the Education of Young Children (NAEYC) warns that, "The appeal of technology can lead to inappropriate uses in early childhood settings" (NAEYC, 2012, p. 4). However, it also asserts that, "When used appropriately, technology and media can enhance children's cognitive and social abilities" (NAEYC, 2012, p. 7). Paediatricians Radesky, Schumacher, and Zuckerman (2015) express the concern that time spent on digital mobile devices, such as tablets, can displace "human interactions and other enriching activities" (p. 3) in the lives of young children. They also note that interactive media "have great potential to promote learning through joint engagement between caregivers and children" (p. 4). Given these seemingly contradictory messages, it is not surprising that educators may be cautious about integrating DT into their programs for young children.

The curriculum for kindergarten in Ontario, The Kindergarten Program (Ontario Ministry of Education, 2016) advocates a play-based approach to learning and teaching:

Play is a vehicle for learning and rests at the core of innovation and creativity. It provides opportunities for learning in a context in which children are at their most receptive. Play and academic learning are not distinct categories for young children, and learning and doing are also inextricably linked for them. It has long been acknowledged that there is a strong link between play and learning for young children. (Ontario Ministry of Education, 2016, p. 18)

Early years educators may fear that DT could inhibit children's ability to be innovative and creative, and that it may limit their learning through "doing." Indeed, some DT programs and apps for young children are more skill-based than creative in nature, and encourage sedentary, solitary practice. As a result, many early childhood professionals report uncertainty about how and when to use DT in their early years classrooms (Beschorner \& Hutchison, 2013). Indeed, although there are hundreds of mobile applications claiming educational value, few reflect principles of constructivist learning necessary for young children (Goodwin \& Highfield, 2012). Without a secure foundation of knowledge and experience with which to evaluate and integrate DT, early childhood educators may struggle to incorporate it into their programs.

Open-ended tablet apps, when offered to children in play-based programs, may provide the opportunity to overcome the drawbacks of some DT and capitalize on its rich learning potential. Tablet apps that offer multimodal communication tools such as photography, drawing, video, and audio recording can be used by young children to enhance their play and deepen their explorations. By giving children new tools to influence their learning environment and create play scenarios, open-ended apps can provide increased agency to explore new identities in multimodal ways.

This research study examined how kindergarten children enacted digital literacy identities as they documented their thinking and learning using open-ended tablet apps in play-based programs. Literacy in this study is defined broadly as meaning-making in multiple forms, including visual, oral, print, and digital. Literacy activities in these 
classrooms are often social and collaborative in nature, and are integrated into play and other content areas such as math and science. The classrooms in the study are situated in two large urban school boards in Ontario. The children come from families that are culturally, linguistically, and economically diverse. Children enter the kindergarten program in the year that they turn four and stay for two years. The open-ended apps complement a play-based approach to learning and teaching. All children were able to explore and document their learning in ways that met their individual learning needs through the multimodal tools provided in the iPad apps and the resources and materials provided by the programs.

\section{Theoretical Perspectives}

This study utilizes four components of multiliteracies theory (New London Group 1996). We view students' multimodal creations as instances of situated practice as Rowsell, Kosnik, and Beck (2008) describe it, "situated practice activities locate teaching within student skill sets; textural practices; texts and lifeworlds" (p. 54). The open-ended tablet apps the children used in this study allowed them to represent their world and their work in a variety of modes that met their individual interests, experiences, and skill levels.

A second component, the notion of overt instruction (New London Group, 1996) as interpreted by Mills (2006), was evident in this study. Mills interprets overt instruction to include a carefully designed program intended to scaffold student learning (2006). In this study, the children worked with the tablet apps within the play-based, inquiry-focused kindergarten program in Ontario. This program is specifically designed to encourage and support active, child-centred learning and thus the program facilitated the successful use of the open-ended apps. As Prinsloo and Rowsell (Prinsloo, 2005; Prinsloo \& Rowsell, 2012) remind us, context matters. The iPads as "placed resources" (Prinsloo, 2005, p. 96) functioned as tools the children were able to use to expand and deepen their meaningmaking in part due to the support offered by the play-based program.

We viewed the children's work through the lens of critical framing, a third component of multiliteracies theory (New London Group, 1996). Although most of the kindergarten students in the study were not yet reading print, they were critically reflecting on visual and auditory texts that they or their classmates created and archived, considering them from different perspectives. Furthermore, they were able to incorporate images and ideas from popular culture and talk back to them by interweaving them with their own stories. The fourth element, transformed practice, as described by Mills (2006) involves a level of creative change through making connections to their learning and culture. Students are seen as active producers, rather than passive consumers of knowledge (Rowsell \& Harwood, 2015). Transformed practice was clearly seen in this study as the children developed their ability to create longer, more complex and varied multimodal slideshows over the two years of the study.

The use of iPads and open-ended apps expands the range of modes that young children have available to them as they make meaning. Rather than just drawing and writing with traditional tools, they have access to photography, video, audio, clip art, etc., which they can use in isolation or in combination (Rowsell, 2017). This multimodal approach to literacy helps to reveal children's interests, motivations, and different pathways to literacy (Kress, 1997). As Gee (2005) reminds us, new technology allows for thinking and making meaning differently, "learning in a new domain ... requires the 
learner to take on a new identity" (p. 34). Through open-ended mobile apps, young children can interweave the many physical and digital texts in their lives to represent what is meaningful to them (Burnett et al., 2014). Young children need time and space to engage with the multiplicity of literacy texts that they encounter. Role-play is a necessary part of this process (MacKey, 2011). Through role-play, children can experience the thoughts, feelings, and behaviours that ground different identities, informed by the texts they have experienced. Open-ended mobile tablet apps can offer one way to engage in, document, and reflect on meaning-making role-play activities.

\section{Methodology}

This paper reports on the first two years (2015/2016-2016/2017) of a three-year study in which we are following 14 kindergarten classrooms in Ontario as they used openended tablet apps (30 Hands and Explain Everything) in their play-based programs. The tablet apps were used mostly during open-ended activity time when children had access to blocks, construction toys, art materials, and pretend play props, but also during outdoor play and more focussed literacy activities. Most classrooms had two educators (27 educators in year 1 in total, and 25 educators in year 2 in total). The educators, registered early childhood educators (RECEs) and Ontario certified teachers (OCTs) in full-day kindergarten core day classrooms and before and after school kindergarten classrooms, were all interviewed before the study began to determine their experiences with DT and their attitudes towards using DT with young children. At the end of year one they were interviewed again to see if their attitudes towards using DT with young children had changed, and to learn about what they perceived to be the challenges and benefits of using the tablet apps in their programs to support literacy learning.

At the beginning of year two they completed a questionnaire on similar topics and were interviewed again at the end of the second year. All educators attended a focus group each year. The interviews were recorded and transcribed, and detailed notes were taken during the focus groups. Classrooms were observed biweekly using participant observation. Kindergarten students had individual accounts in the tablet apps where they could archive their slideshows. Samples of student digital slideshows were collected and analyzed. The research team viewed the archived slideshows and noted the costumes and/or artifacts the children used, the content of their drawings, and the language they used and categorized the digitally recorded play episodes according to the identity the children appeared to be enacting. When a team member was present for the slideshow creation, observations of the process were included in the analysis. The research team all held RECE qualifications or were RECEs in training. The principal investigator also held an OCT qualification.

\section{Students as Experts}

\section{Findings}

The embodied experience of using an iPad, an adult "expert" device, allowed children to take on 'expert' identities. Some of the most popular identities explored through play were photographer, reporter, film-maker, teacher, and scientist. Students used the photo, video, and audio tools within the apps to document their indoor and outdoor environment, artifacts they had created, actions they had prepared, and each other. When students first began photographing each other, some students complained that they hadn't 
given their permission to have their images in a slideshow. They recognized their ownership of their own image and sought to retain control of it. As photographers, they learned to ask permission of their classmates and teachers before taking a photo. A popular activity was to take a photograph of themselves or a classmate and then embellish the photo by drawing over top, sometimes completely covering the original image as seen below. These were occasions of great interest to the photographer and other students and often led to hilarious laughter. Sometimes, in the role of a journalist, the children added audio recorded commentary or interviewed the subject as part of their slideshow.

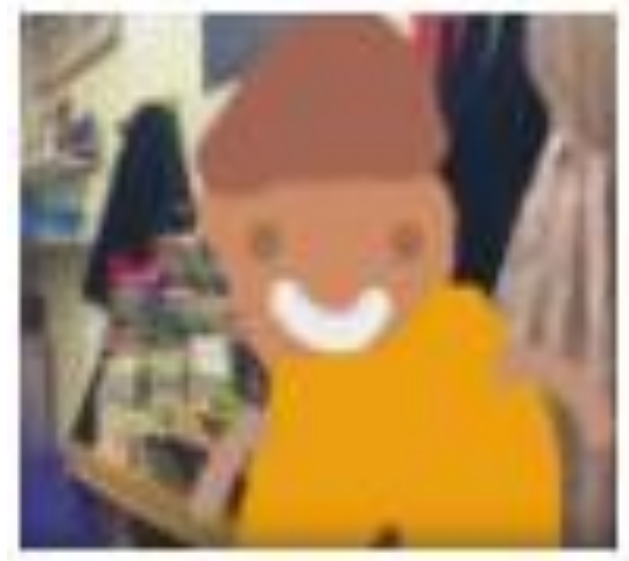

Figure 1. An Embellished Selfie

The students' photo explorations situated their literacy practices squarely in the "lifeworld" (Rowsell, Kosnik, \& Beck, 2008) of their kindergarten classrooms. The multimodal apps gave them the power not only to choose the content of their photos (themselves and their peers) and independently take the photos, but also to alter them according to their interests. Typically, children in kindergarten are most often an adult photographer's subject matter. Young students are neither given cameras nor other devices to take photos nor tools to critically frame their photos (New London Group, 1996). As in Dockett and Perry's (2005) research with kindergarten children, the students could photograph their school world from their own perspectives, and could reflect on the photos and comment on their meaning. In Dockett and Perry's research (2005), the children commented orally on the photos. In the case of this study, the children could immediately see the photos on their iPads, reflect and comment on them, and then alter them in ways that were personally relevant. The agency afforded by this open-ended, multimodal app positioned students as active producers of the digital content rather than passive subjects. While traditional role-play is a common practice for young children, role-play mediated through the open-ended tablet apps enhanced both the children's agency and their meaningmaking opportunities within the play-based program.

Dylan's Story. In the following case study, we see a young child role-playing a number of identities using the multimodal affordances of the open-ended apps, including storyteller, artist, photographer, director, and teacher. In the first year of the study, Dylan, a four-year-old in the first year of the two-year kindergarten program, was reluctant to draw or write using traditional tools, and, according to his teacher, his oral storytelling skills 
were very limited. However, using the 30 Hands app, he created a six-slide story with drawings of his family members and a photograph of the sky out the window. He then added audio recordings to accompany the drawings on each slide: "I love my mommy, I love my daddy, I love my sister, I love the sky, I love everybody." He then wrote the words "I love" with his finger on a final slide, asking a research team member for the spelling of the word "love." Below is the first slide of "mommy" and the last slide of the slideshow.
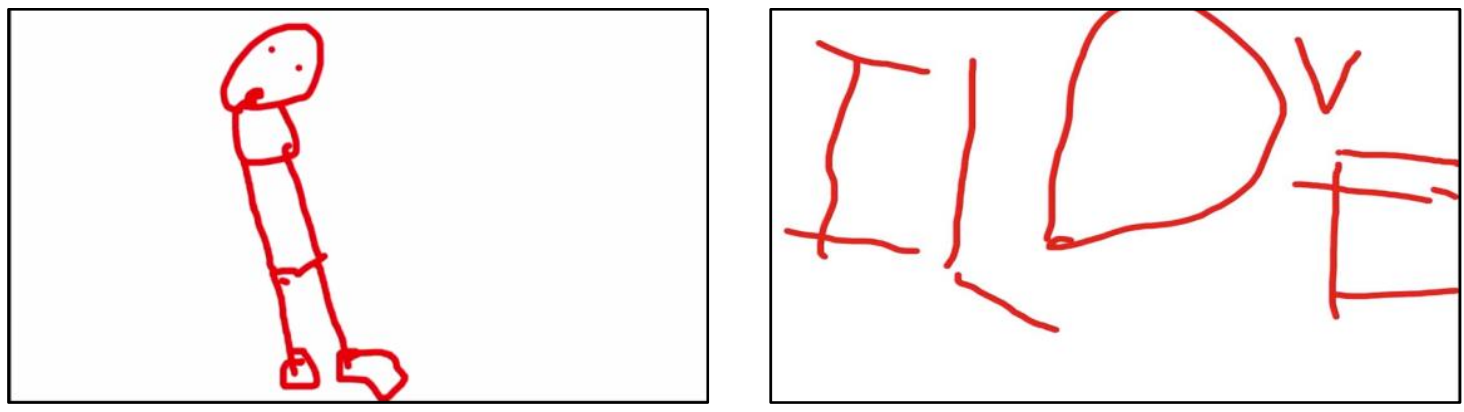

Figure 2. Dylan's Family Story

Dylan's teacher was incredulous. She did not know that he was capable of this level of literacy production. She reported that he had spent far more time drawing and then recording audio for this text than any other activity he had engaged in up to that point. It was also the most coherent and well-developed story he had expressed in any medium. Dylan also seemed incredulous. Although he typically did not readily engage with the other children in the class, he eagerly played his slideshow to several children in the class.

By year two of the project, Dylan had transformed from a reluctant student to an enthusiastic teacher. Dylan took on the role of director, asking the teacher to video record him while he demonstrated and described, in the role of a teacher, how two triangular prisms when combined turn into a cube. Below is a still from the video. He asks, "What happens when you put two triangular prisms together? You are right! [demonstrating for the camera] They turn into a cube!" Dylan appeared to feel very comfortable playing out his geometry knowledge, and engaging his teacher as his assistant.

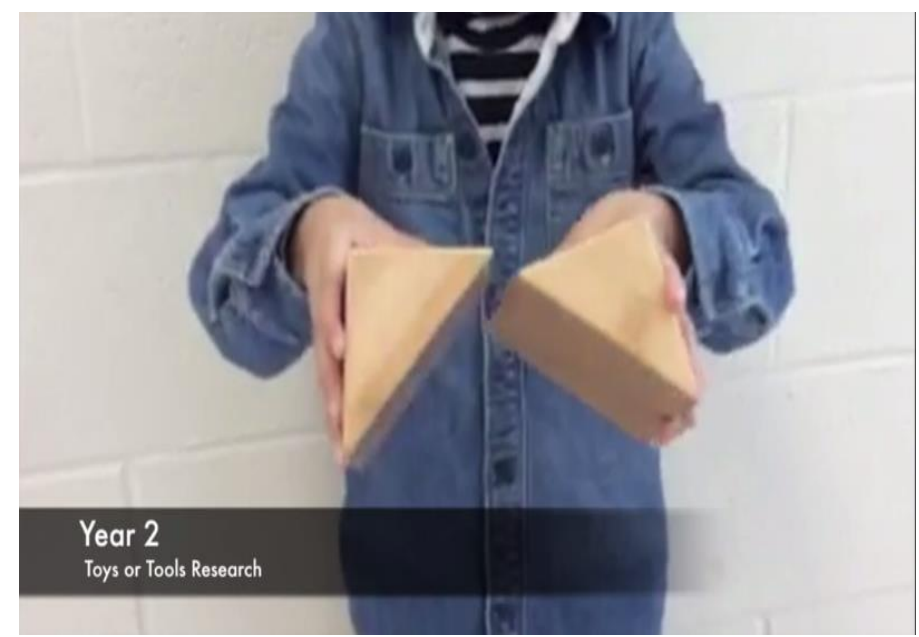

Figure 3. Dylan as Geometry Teacher 
Although Dylan was still not an enthusiastic writer with traditional tools by the end of his second year of kindergarten, the multimodal tools within the apps motivated him to powerfully communicate ideas as wide-ranging as his love for his family to his understanding of geometry. This learning was facilitated by the context, that is, the carefully designed play-based program that scaffolded his technology use (Mills, 2006; Prinsloo, 2005, Prinsloo \& Rowsell, 2012). He, like his peers, was given time, support, resources, and encouragement to explore his learning with "real" and virtual tools. The open-ended apps, offered within a play-based program, led to a transformation in Dylan's literacy practice (New London Group, 1996; Mills, 2006). His identity shifted from that of a reluctant reader and writer to an effective multimedia communicator.

\section{The Power of Independence}

The affordances of the iPad and open-ended apps allow young children to document their thinking and perspectives in ways that overcome the limitations of their age. At age four or five, most are not yet proficient in conventional reading and writing, and have not fully developed their fine motor control over tools. However, using the iPad apps, they can independently present information and communicate ideas in a quick, efficient, and more professional-looking manner than with traditional kindergarten tools such as paint or markers.

The 30 Hands app has background scenes that the children can use as a canvas on which to create their stories. A popular backdrop in this project was an outer space scene. Ella, who created the slide below, appeared to be excited by both the "real" looking backdrop, but also by her own creative additions. After choosing the space backdrop, she drew additional elements with her finger, changing colours often, and then audio recorded over the image. Below the image of her slide is a transcript of her audio recording.

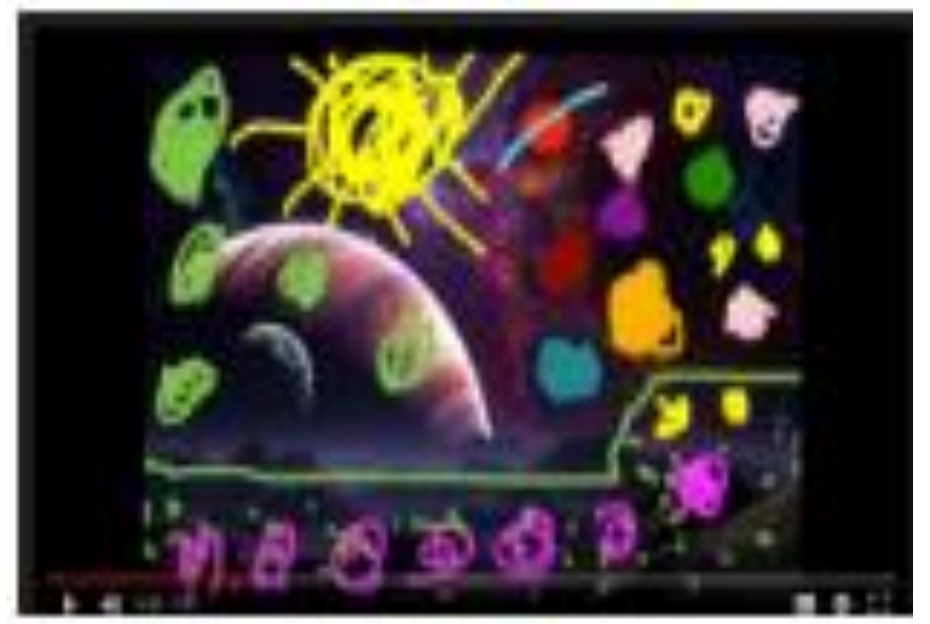

Figure 4. Ella's Depiction of Space

This is space. And then I created all the planets including Saturn. I put rainbows, I put dots. It totally looks like space. And I put the sun, I put everything! It looks so wonderful, you should actually see it! It looks so wonderful, you should see it! You should see it! (Transcript of Ella's Depiction of Space) 
The pre-made outer space scene provided Ella with a foundation or scaffold (Mills, 2006) and perhaps inspiration for her dynamic and descriptive slideshow, but the open-ended nature of the app and the multi-modal tools within it enabled her to independently craft a complex identity. She clearly views herself as a creator ("I created all the planets") and someone knowledgeable about space, naming a specific planet, Saturn, and the sun. She also positions herself as competent and powerful, as she describes her accomplishment ("I put everything") and takes pride in what she has done ("It looks so wonderful"). She is also clearly taking on the role of a promoter. She speaks directly and enthusiastically to a future, unseen audience, inviting them three times to view her slideshow ("You should actually see it...Y You should see it! You should see it!") Through creating a digital drawing, audio recording a detailed description, and inviting a future audience to enjoy her creation, she is utilizing the multimodal tools in the app to independently perform a complex identity (Wohlwend, 2009).

\section{Archival Reflection}

Within the apps, the children could save their slideshows in their own digital folders. In this way, they could carry their archived work with them around the classroom. Like an artist or draftsperson, they could easily show their portfolio of work to others, opening up opportunities for reflection and collaboration with peers, educators, and family members. Many children regularly looked at their own and others' digital slideshows and were inspired to discuss them, embellish them, or add new slideshows on the same theme. This archival affordance scaffolded reflection and encouraged children to continue to explore their interests over time. In the following case study, Jasper, aged five, is motivated to explore his interest in the pop culture figure Pikachu and critically reframe it (New London Group, 1996) incorporating his own interests and creative skills.

Jasper and Pikachu.Jasper is quite enthusiastic about Pokemon, specifically a character within the series named Pikachu. His archived slideshows contain many scenes depicting Pikachu expressing a variety of emotions in different settings. The drawings usually incorporate a built-in background, space being a popular choice for Jasper. At the time of the following observation, many children in North America were consumed by a mobile game called Pokemon Go (Niantic, 2016), where Pokemon seemed to appear on a mobile device in the real world and children had the chance to "catch" them. The game often has updates where new characters or features are added to the game, including the addition of a Santa hat on top of Pikachu.

One day, Jasper gave a research team member a curated tour of his slideshow archive. As he shuffled through the slideshow images, they had the following exchange:

Jasper: Some of these pictures aren't mine. This one is mine! (Selecting a picture of a space background with yellow circles drawn over it). This is what it looks like when you blast off. I know because I saw the Rangers do it.

Research team member: Are the Rangers Pokemon?

Jasper: They're the bad guys that try to catch all the Pokemon (opening a blank slide and filling the screen with light blue). I'm going to draw another Pikachu (beginning to add yellow on top of the blue). I'm going to make a winter scene. 
Research Team member: Have you seen the Santa hat Pikachu they released in the Pokemon Go game?

Jasper: No! I didn't know that! (Drawing a Santa hat on the head of the Pikachu he created). Did it look like this?

Research team member: It looked exactly like that!

Jasper: I'm going to make this one have an open mouth. He's going to be happy. See? I know how to make an open mouth" (finishing his drawing and saving his work). This is the best Pikachu I have ever drawn.

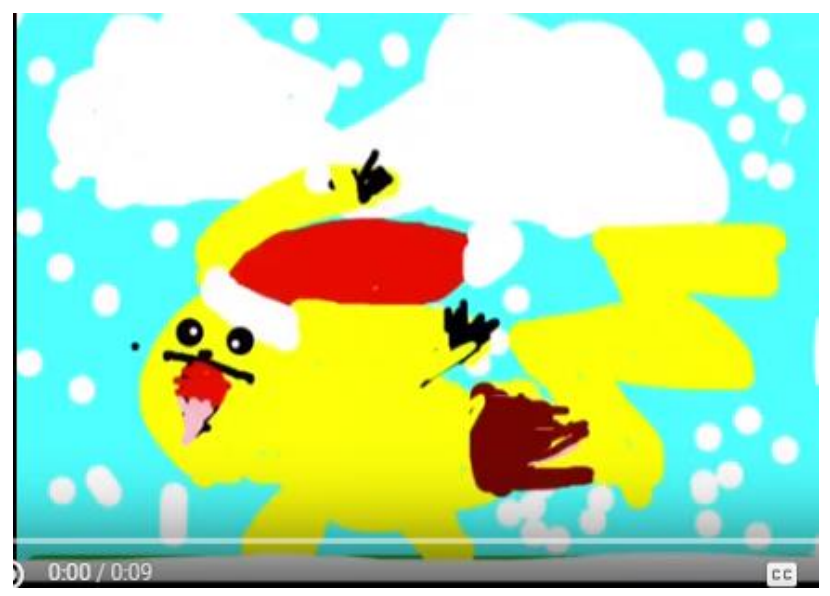

Figure 5. Jasper's Santa Pikachu

Jasper again showed the research assistant all the Pikachu slides he had made previously. As he was doing so, he explained different aspects of each drawing, saying "this one is angry," "this Pikachu is in space," and, "I tried this but I didn't like it." Jasper opened his recently created Santa Pikachu and said, "I really like this one. It's the only Pikachu in snow I've made." He then added to the slideshow by audio recording a dramatic re-enactment of the sound a Pikachu makes, "Pika, Pika, Pika. Pikachu!"

In the context of the play-based kindergarten, Jasper had the time and digital and social resources to explore and critically reframe (New London Group, 1996) his interest in a pop culture phenomenon, Pokemon. He was comfortable sharing his digital drawings and making connections to his out-of-school experiences ("I know because I saw the Rangers do it"). The research team member, like his kindergarten educators, encouraged him to discuss his interests ("Are the Rangers Pokemon?"), positioning him as an expert. Perhaps due to the encouragement he was receiving, he begins to draw on a blank slide and narrate his actions. Further entering into Jasper's world, the research team member offers some new information about Santa Pikachu. This information is enthusiastically received and inspires Jasper to create what he imagines Santa Pikachu would look like. Jasper then transitions from depicting Pikachu as he has seen it or imagines it to look, to planning what his own version will look like and what emotion it is going to portray ("I'm going to make this one have an open mouth. He's going to be happy"). He then evaluates his finished work, proudly describing his drawing skill ("See? I know how to make an open mouth") and announcing that he has exceeded his previous Pikachu achievements ("This is the best Pikachu I have ever drawn!") After this interactive exchange, Jasper again reviews his Pikachu slides with the research team member, but this time he is more detailed in his 
reflections, referring to the emotions of the character, the backgrounds, and his earlier attempts.

Using the open-ended app gave Jasper the opportunity to engage in digital role-play and represent his interest in Pikachu in a way that motivated him to continue to explore his abilities and his knowledge about Pokemon. The open-ended nature of the app afforded Jasper a multimodal experience that captured not only his interest, but also enabled him to showcase his knowledge about this aspect of popular culture. The context, an open play period in which the educators encouraged and supported students to explore their interests, was another key factor in this interaction. Having an adult who was responsive and engaged contributed to Jasper's meaning-making around the character and story of Pikachu, and his experimentation with drawing and audio recording. He was motivated to incorporate new information and attempt new forms of representation. The research team member, an RECE in training, was enacting the role advocated in the Ontario kindergarten curriculum, "As the children express their thinking, educators think about questions they can ask that will further provoke children's thinking and continue to stimulate their curiosity and wonder" (Ontario Ministry of Education, 2016, p. 21).

As in the previous examples with Dylan and Ella, we can see how proud Jasper is of his accomplishments and how excited he is to share his creations. In all three cases, the affordances of the open-ended apps intersected with the scaffolding provided by the context, including large periods of play time, physical resources such as blocks, and the social and pedagogical support of student-led inquiry, to enable instances of identity exploration and enthusiastic meaning-making.

\section{In-Depth Exploration}

While enacting roles such as teacher, scientist, performer, journalist, or architect with the iPad apps, many children exhibited motivation to represent their understandings with greater length, complexity, and variety of modes than they exhibited with traditional literacy tools and practices. Below are two slideshows created by Aisha. She has documented her exploration of the identities of architect and builder in four interrelated modes: with physical objects, with photography, with text, and with audio recording. Aisha began by building a small block structure on a counter using a few blocks of one type. She photographed it and labelled it using the text feature within the app, "DES is a letal cassol" [This is a little castle]. She then audio recorded what she had written on the slide. It is interesting to note that she used phonetic spelling, and pronounced the words exactly as she had written them.

At a later date, Aisha returned to castle building, this time creating a much more elaborate structure using tree cuts, wooden spools, and stones. The structure is far more castle-like with outer and inner rings representing walls and towers in the centre. On this much more elaborate, layered structure she wrote, "des is the casol its reli big" [This is the castle. It's really big.] She also audio recorded this message on the slide. 

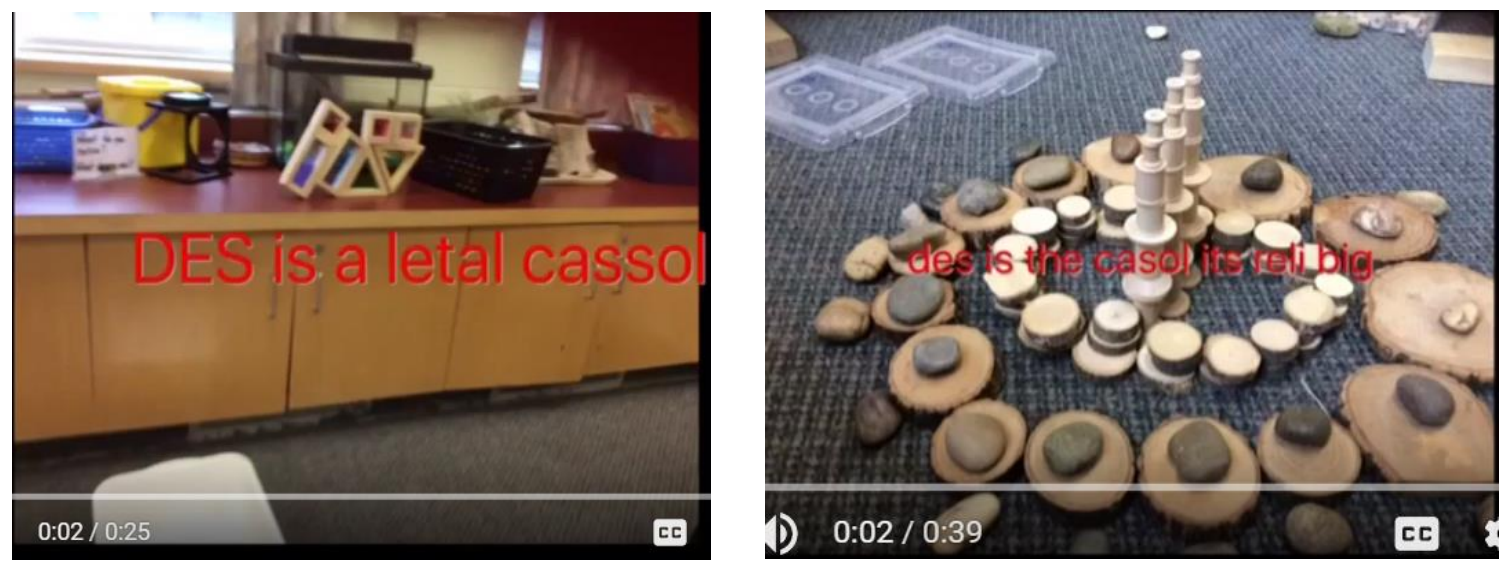

Figure 6. Aisha's Earlier and Later Castle Creations

As with the example of Jasper and his drawings of Pikachu, being able to reflect back on an earlier slideshow inspired Aisha to return to an earlier subject of interest and explore it more deeply. Aisha is clearly referencing her earlier work and comparing it to her new work. She has used the same form of documentation (photo, superimposed text, audio recording of the text) on both slides. She has also used the same type of labelling language (This is...) and comparative language (little and really big).

In terms of the increased complexity of her work, Aisha moved from using a few items of one type of material in a simple stacked structure, to a greater number and variety of materials in a more complex structure. In the second structure, there are three types of rings: an outer ring of stones, an inner ring of stones placed on top of larger wood cuts, and an innermost ring of small stacked wood cuts. These three concentric rings surround a series of towers made of stacked wooden spools of decreasing size. Clearly, this second structure would have taken a great deal more planning, time, and careful execution. Aisha notes this significant achievement in her typed and audiotaped description. She does not simply describe the two structures as little and big, but as little and really big.

The open-ended play periods in this class and the availability of a range of building materials set the scene for the development of Aisha's exploration of building. Typically block structures made in a kindergarten class would need to be put away at the end of the activity period, but because Aisha could document the first structure on an iPad and reflect back on the slideshow at a later date, she could transform her practice by building on her earlier exploration and developing a more complex manifestation of her thinking.

\section{Discussion}

The four components of multiliteracies theory are useful tools for examining how DT, when incorporated into a play-based kindergarten program, can enrich and enhance literacy learning and teaching. Situated practice (New London Group, 1996) was evident in that the open-ended apps supported and encouraged children to interweave the many texts in their lives (i.e., movies, TV, videogames, books, signs, school curriculum, everyday encounters, etc.) (Rowsell, et al., 2008). Through role-play that incorporates open-ended tablet apps, they could explore the personal meaning of these texts as they worked to craft their growing understanding of the world and of themselves through critical framing (New London Group, 1996). As a result, the children's work with the apps in this 
study did not supplant the powerful meaning-making practices inherent in role-play, nor did the apps reduce the creativity and problem-solving possibilities of play. Instead, they added an array of multimodal tools that encouraged deeper explorations.

The multimodal affordances of the open-ended apps (photography, video, drawing, text, audio recordings, alone and in combination) allowed young children to represent and communicate their understandings in ways that were motivating and met the needs and interests of students at a wide range of language and literacy skill levels. They were roleplaying with "real" technology, not toys, and producing "real" texts which approximate adult digital products. Over time, evidence of transformed practice (Mills, 2006) could be seen in their digital slideshows which showed a marked increase in length, complexity, and variety of modes of representation. The children actively incorporated the affordances of the open-ended apps into more traditional aspects of their play such as building structures, pretend play, drawing, and storytelling. Lastly, the play-based kindergarten program in which the children were given the time, space, resources, and encouragement to play out and document their ideas constituted overt instruction, as defined by Mills (2006).

There were several factors that facilitated the app-mediated identity exploration through role-play that occurred in this study. The first was the open-ended nature of the apps themselves. The apps had virtually no content other than a few backdrops, but they had many child-friendly tools for exploring, creating, and documenting meaning. The mobile nature of the iPads allowed and encouraged the children to take these thinking and documentation tools to locations that were rich with meaning for them, whether that be the classroom floor, the block centre, the pretend play corner, or out on the playground. While the children eagerly integrated the iPads and apps into their play, the fact that iPads are a "grown-up" device and not a toy appeared to add to their allure.

Unlike apps that are designed for teaching or practicing specific skills or curriculum content, these open-ended apps allowed the children to respond to and interpret the social and physical context around them in ways that were meaningful to them (Prinsloo, 2005; Prinsloo \& Rowsell, 2012). Unlike digital games which can disrupt the intrinsic meaning, motivation, and autonomy inherent in play by imposing rules, goals, and rewards (Nolan \& McBride, 2014), the open-ended apps kept the children firmly in the driver's seat.

Although there is now a considerable body of research attesting to the benefits of DT for early years learning and teaching, including studies of multimodal literacy learning with iPad apps (e.g., Falloon \& Khoo, 2014; Harwood, 2017; Roswell \& Harwood, 2015), many early years professionals are hesitant to include DT into their programs. They may be right to be cautious. Not all DT is designed to encourage and support the type of intrinsically motivated and context specific multimodal meaning-making that play affords. Educators need to carefully choose and evaluate different forms of DT to ensure that they meet their learning and teaching goals. However, typically there is little pre-service or inservice guidance for early years educators to support them in this endeavor.

Furthermore, beyond choosing appropriate technology, educators face the difficult tasks of learning and teaching the technical aspects of the devices and apps, facilitating the integration of the technology into their programs, adapting or creating new teaching strategies, and learning to "see" DT mediated learning which can look different than traditional learning products and processes. We have written about these issues elsewhere in more detail (e.g., McGlynn-Stewart, Maguire, Mogyorodi, Brathwaite, \& Hobman., in press; McGlynn-Stewart, et al., 2017a; McGlynn-Stewart, et al., 2017b). In this study, the 
educators had the support of research team members who visited biweekly to observe and participate over two academic years, giving technical and pedagogical support when requested.

This study suggests that open-ended tablet applications can provide children with additional tools to actively explore, create, document, and reflect on their learning in many modes, when implemented within a play-based program, and when educators are given appropriate professional learning support. Rather than supplanting non-digital meaningmaking practices such as role-play, children can fold digital affordances into their play in ways that expand the range of identities they explore and the tools and practices with which to explore them.

\section{References}

Beschorner, B. \& Hutchison, A. (2013). iPads as a literacy teaching tool in early childhood. International Journal of Education in Mathematics, Science and Technology, 1(1), 16-24.

Burnett, C., Merchant, G., Pahl, K., \& Rowsell, J. (2014). The (im)materiality of literacy: The significance of subjectivity to new literacies research. Discourse: Studies in the Cultural Policies of Education, 35(1), 90-103.

Blagojevic, B., Brumer, H., Chevalier, S., O’Clair, A., \& Thomes, K. (2012). Touch and grow: Learning and exploring using tablets. Teaching Young Children, 6(1), 1821.

Dockett, S. \& Perry, B. (2005). 'You need to know how to play safe': Children's experiences of starting school. Contemporary Issues in Early Childhood, 6(1), 418.

Falloon, G. \& Khoo, E. (2014). Exploring young students' talk in iPad-supported collaborative learning environments. Computers \& Education, 77, 13-28.

Fleer, M. (2014). The demands and motives afforded through digital play in early childhood activity settings. Learning, Culture and Social Interaction, 3, 202-209.

Gee, J. P. (2005). Good video games and good learning. Phi Kappa Phi Forum, 85(2), 33-37.

Goodwin, K., \& Highfield, K. (2012, March). iTouch and iLearn: An examination of "educational" apps. Paper presented at the Early Education and Technology for Children conference, Salt Lake City, UT.

Harwood, D. (2017). Crayons and iPads: Learning and teaching of young children in the digital world. Thousand Oaks, CA: Sage.

Herro, D. (2015). Sustainable innovations: Bringing digital media and emerging technologies to the classroom. Theory Into Practice, 54(12), 117-127.

Kress, G. (2010). Multimodality: A social semiotic approach to contemporary communication. London: Routledge.

Lee, T. H., Wu, F. G., \& Chen, H. T. (2017) Innovation \& evaluation of tangible direct manipulation digital drawing pens for children. Applied Ergonomics, 60, 207-219.

MacKey, M. (2011). The embedded and embodied literacies of a young reader. Children's Literature in Education, 42, 289-307.

McGlynn-Stewart, M., Brathwaite, L, Hobman, L., Maguire, N., Mogyorodi, E., \& Park, Y. (2017a). Inclusive teaching with digital technology: Supporting literacy learning in play-based kindergartens. Learning Landscapes, 11(1), 199-216. 
McGlynn-Stewart, M., MacKay, T., Gouweleeuw, B., Hobman, L., Maguire, N., Mogyorodi, E. \& Ni, V. (2017b). Toys or tools?: Educators' use of tablet applications to empower young students through open-ended literacy learning. In M. Mills \& D. Wake (Eds.), Empowering Learners with Open-Access Learning Initiatives (pp. 101-123). Hershey, PA: IGI Global.

McGlynn-Stewart, M., Maguire, N., Mogyorodi, E., Brathwaite, L., \& Hobman, L. (in press). The highs and lows of mobile digital technology integration in kindergarten. In Y. Zhang \& D. Cristol (Eds.), Handbook of Mobile Teaching and Learning (2nd ed). New York, NY: Springer Publishing.

Mills, K. A. (2006). Multiliteracies: A critical ethnography: Pedagogy, power, discourse and access to multiliteracies (Unpublished doctoral dissertation). Queensland University of Technology, Brisbane, Australia.

National Association for the Education of Young Children. (2012). Technology and interactive media as tools in early childhood programs serving children from birth through age 8. A joint position statement of the National Association for the Education of Young Children and the Fred Rogers Center for Early Learning and Children's Media at Saint Vincent College. Retrieved from: https://www.naeyc.org/sites/default/files/globallyshared/downloads/PDFs/resources/topics/PS_technology_WEB.pdf

Neumann, M. M. (2016). Young children's use of touch screen tablets for writing and reading at home: Relationships with emergent literacy.Computers \& Education, 97, 61-68.

New London Group. (1996). A pedagogy of multiliteracies: Designing social futures. Harvard Educational Review, 66(1), 60-93.

Niantic. (2016). Pokemon Go. [Mobile Application Software]. Retrieved from: http://itunes.apple.com.

Ontario Ministry of Education. (2016). The kindergarten program 2016. Toronto, ON: Author.

Nolan, J. \& McBride, M. (2014). Beyond gamification: Reconceptualizing game-based learning in early childhood environments. Information, Communication \& Society, 17(5), 594-608.

Prinsloo, M. (2005). The new literacies as placed resources. Perspectives in Education, 23(4), 87-98.

Prinsloo, M. \& Rowsell, J. (2012). Digital literacies as placed resources in the globalized periphery. Language and Education, 26(4), 271-277.

Radesky, J. S., Schumacher, J., \& Zuckerman, B. (2015). Mobile and interactive media use by young children: The good, the bad, and the unknown. Pediatrics, 135(1), $1-3$.

Rowsell, J., Kosnik, C., \& Beck, C. (2008). Fostering multiliteracies pedagogy through preservice teacher education. Teacher Education, 19(2), 109-122.

Rowsell, J. \& Harwood, D. (2015). "Let It Go": Exploring the image of the child as a producer, consumer, and inventor. Theory Into Practice, 54(2), 136-146.

Rowsell, J. (2017). Be the 'I' in iPad: iPads and the children who love them. In D. Harwood (Ed.), Crayons and iPads: Learning and teaching of young children in the digital world (pp. 6-15). Thousand Oaks, CA: Sage.

Wohlwend, K. E. (2009). Early adopters: Playing new literacies and pretending new 
technologies in print-centric classrooms. Journal of Early Childhood Literacy, 9(2), 117-140.

Wong, S. S. (2015). Mobile digital devices and preschoolers' home multiliteracy practices. Language and Literacy, 17(2), 75-90.

Yilmaz, R. M. (2016). Educational magic toys developed with augmented reality technology for early childhood education. Computers in Human Behaviour, 54, 240-248.

Author Biographies

Monica McGlynn-Stewart (Ph.D.) is a professor in the School of Early Childhood at George Brown College, Toronto, Ontario. She teaches courses in curriculum, policy, and research methods. She is a former elementary teacher, principal, and consultant. Currently, she is the Principal Investigator on the federally funded research project, Toys or Tools? Using Tablet Applications for Open-Ended Literacy Learning. Her research interests include teacher action research, student engagement, literacy learning and teaching in the early years, and digital technology mediated learning and teaching.

Leah Brathwaite is a graduate of the Early Childhood Leadership degree program at George Brown College. She has a background in computer technology, and works fulltime as an Early Childhood Educator to children from kindergarten to Grade 7. She was a Research Assistant on the federally funded research project, Toys or Tools? Using Tablet Applications for Open-Ended Literacy Learning. Her research interests include early childhood program quality, literacy learning in the early years, and digital technology use in the early years.

Lisa Hobman is a graduate of the Early Childhood Leadership degree program at George Brown College. She is currently working with the YMCA of the Greater Toronto Area as a Registered Early Childhood Educator (RECE). She was a Research Assistant on the Toys or Tools? project since the beginning and hopes to continue studying the impact of technology on early years pedagogy in a Masters program in the near future.

Nicola Maguire (MA) is a part-time faculty member in the School of Early Childhood at George Brown College and a Research Assistant on the federally funded research project, Toys or Tools? Using Tablet Applications for Open-Ended Literacy Learning. She also supports students in school settings with their use of assistive technology devices. Her research interests include children's outdoor play, digital technology uses for learning and teaching, and arts-based curriculums.

Emma Mogyorodi (B. ECL, RECE) is a graduate student at Ryerson University. She also teaches an early childhood musicianship class in Toronto. She previously served as the Early Childhood Music Coordinator at The Royal Conservatory. In addition to her studies and teaching, she works as a research assistant for Toys or Tools? Using Tablet Applications for Open-Ended Literacy Learning. Her research interests include digital technology, literacy learning, and music education. 